Supporting Information.

\title{
Verification of a Designed Intra-molecular Hydrogen Bond in a Drug Scaffold by Nuclear Magnetic Resonance Spectroscopy
}

\section{Ariane Jansma, ${ }^{\dagger}$ Qiong Zhang, ${ }^{\dagger}$ Bing Li, ${ }^{\dagger}$ Qiang Ding, ${ }^{\dagger}$ Tetsuo Uno, ${ }^{\dagger}$ Badry Bursulaya,${ }^{\dagger}$ Yi Liu, $^{\dagger}$ Pascal Furet, ${ }^{\ddagger}$ Nathanael S. Gray ${ }^{\dagger}$ and Bernhard H. Geierstanger ${ }^{*, \dagger}$}

Genomics Institute of the Novartis Research Foundation

10675 John Jay Hopkins Drive, San Diego, CA 92121, USA

Novartis Institute for Biomedical Research, CH-4002 Basel, Switzerland

Supporting Information Available: Chemical shift assignments and synthesis of $\mathbf{6}$. This material is available free of charge via the Internet at http://pubs.acs.org.

Table S1. Chemical shift assignments of 6 from ${ }^{1} \mathrm{H}-\mathrm{COSY}$ and ${ }^{1} \mathrm{H}-{ }^{15} \mathrm{~N}$ HMBC spectra (146 mM in deuterated DMSO, $300 \mathrm{~K}) .{ }^{1} J_{\mathrm{HN}}$ couplings are approximately $91.8 \mathrm{~Hz}$ for HN11 and $92.8 \mathrm{~Hz}$ for HN14. Proton chemical shifts are relative to TSP (labeling according to Figure 2). *Estimated from nitrogen chemical shift of a folded peak at $253.0 \mathrm{ppm}$; n.a. = not applicable ${ }^{13} \mathrm{C}$ chemical shifts were determined with a sample previously dissolved in phosphate buffer, lyophilized and redisolved in DMSO.

\begin{tabular}{|c|c|c|c|}
\hline Atom/Group & ${ }^{1} \mathrm{H} \delta$ [ppm] & ${ }^{13} \mathrm{C} \delta[\mathrm{ppm}]$ & ${ }^{15} \mathrm{~N} \delta[\mathrm{ppm}]$ \\
\hline N1 & n.a. & n.a. & 228.4 \\
\hline $\mathrm{CH} 2$ & 8.51 & 152.4 & n.a. \\
\hline N3 & n.a. & n.a. & 220.5 \\
\hline $\mathrm{C} 4$ & n.a. & 148.8 & n.a. \\
\hline $\mathrm{C} 5$ & n.a. & 105.1 & n.a. \\
\hline C6 & n.a. & 156.8 & n.a. \\
\hline $\mathrm{CH} 7$ & 6.90 & 102.1. & n.a. \\
\hline $\mathrm{CH} 8$ & 7.79 & 121.4 & n.a. \\
\hline N9 & n.a. & n.a. & 166.3 \\
\hline $\mathrm{CO} 10$ & n.a. & 150.4 & n.a. \\
\hline NH11 & 9.50 & n.a. & 101.9 \\
\hline $\mathrm{CH}_{2} 12$ & 3.56 & 35.1 & n.a. \\
\hline $\mathrm{CH}_{3} 13$ & 1.35 & 15.6 & n.a. \\
\hline NH14 & 8.35 & n.a. & 86.7 \\
\hline $\mathrm{CH}_{2} 15$ & 3.25 & 38.7 & n.a. \\
\hline $\mathrm{CH}_{2} 16$ & 3.88 & 38.2 & n.a. \\
\hline $\mathrm{NH}_{3}^{+}$ & 8.12 & n.a. & $\sim 30.8^{*}$ \\
\hline
\end{tabular}

\begin{tabular}{|c|c|c|c|}
\hline Atom/Group & ${ }^{1} \mathrm{H} \delta[\mathrm{ppm}]$ & ${ }^{13} \mathrm{C} \delta[\mathrm{ppm}]$ & ${ }^{15} \mathrm{~N} \delta[\mathrm{ppm}]$ \\
\hline N1 & n.a. & n.a. & 220.0 \\
\hline $\mathrm{CH} 2$ & 8.01 & 151.0 & n.a. \\
\hline N3 & n.a. & n.a. & 219.9 \\
\hline $\mathrm{C} 4$ & n.a. & 147.7 & n.a. \\
\hline $\mathrm{C} 5$ & n.a. & 104.7 & n.a. \\
\hline C6 & n.a. & 155.7 & n.a. \\
\hline $\mathrm{CH} 7$ & 6.32 & 100.6 & n.a. \\
\hline CH8 & 7.26 & 121.5 & n.a. \\
\hline N9 & n.a. & n.a. & 163.7 \\
\hline $\mathrm{CO} 10$ & n.a. & not det. & n.a. \\
\hline NH11 & 9.08 & n.a. & 106.4 \\
\hline $\mathrm{CH}_{2} 12$ & 3.39 & 35.3 & n.a. \\
\hline $\mathrm{CH}_{3} 13$ & 1.28 & 13.7 & n.a. \\
\hline NH14 & 7.39 & n.a. & 83.9 \\
\hline $\mathrm{CH}_{2} 15$ & 3.34 & 39.1 & n.a. \\
\hline $\mathrm{CH}_{2} 16$ & 3.78 & 38.2 & n.a. \\
\hline $\mathrm{NH}_{3}^{+}$ & $\sim 5.82$ & n.a. & $\sim 30.3^{*}$ \\
\hline
\end{tabular}

Table S2. Chemical shift assignments of 6 from ${ }^{1} \mathrm{H}-\mathrm{COSY}$ and ${ }^{1} \mathrm{H}_{-}{ }^{15} \mathrm{~N}$ HMBC spectra $(96.5 \mathrm{mM}$ in $8.8 \mathrm{mM}$ sodium phosphate buffer, $3.5 \mathrm{mM}$ TSP, $\left.12 \% / 88 \% \mathrm{D}_{2} \mathrm{O} / \mathrm{H}_{2} \mathrm{O}, 300 \mathrm{~K}, \mathrm{pH} 5.05\right)$. The ${ }^{1} J_{\mathrm{HN}}$ coupling for $\mathrm{HN} 11$ is approximately $94.4 \mathrm{~Hz}$. Proton chemical shifts are relative to TSP (labeling according to Figure 2). *Estimated from nitrogen chemical shift of a folded according to Figure 2). *Estimated from nitrogen chemical shift

\footnotetext{
* To whom correspondence should be addressed. Phone: 858-812-1633. Fax: 858-812-1746. E-mail: bgeierst@gnf.org

Genomics Institute of the Novartis Research Foundation

* Novartis Institute for Biomedical Research

a Abbreviations: HMBC, heteronuclear multiple bond correlation; NMR, nuclear magnetic resonance; COSY, correlated spectroscopy.
} 


\section{Synthesis of 6:}

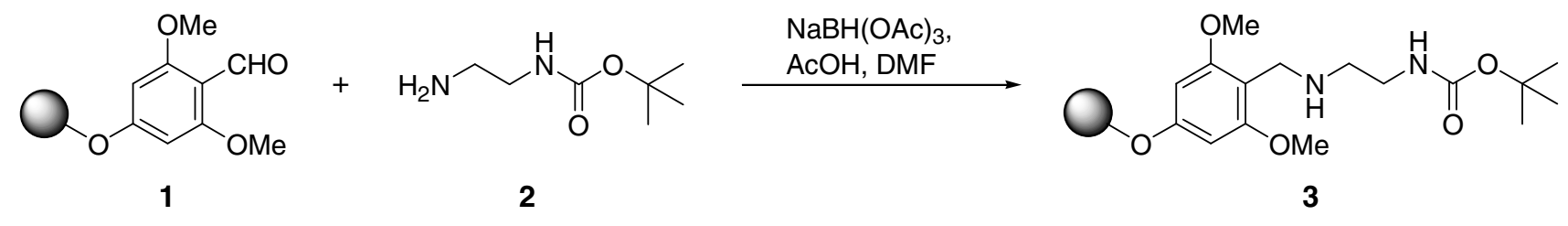

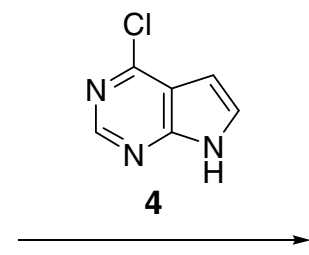

DIEA, n-BuOH

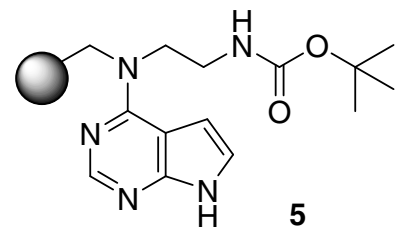

1) Ethyl isocyanate

2) $\mathrm{CF}_{3} \mathrm{COOH}$

Pal Aldehyde resin 1 (200 mg, Midwest Biotech, $1.05 \mathrm{mmol} / \mathrm{g}$ ) was immersed in N, N-dimethylformamide (DMF, $1 \mathrm{ml})$ completely. N-tButoxycarbonyl-1, 2-ethylenediamine $2(96 \mathrm{mg})$ and acetic acid $(96 \mu \mathrm{l})$ were added to the reaction. After the mixture has been shaken at 22 ${ }^{\circ} \mathrm{C}$ for 2 hours, sodium triacetoxyborohydride $(176 \mathrm{mg}$ ) was added in one portion to the reaction; and then newly formed reaction mixture was shaken at $22{ }^{\circ} \mathrm{C}$ for an additional 16 hours. The resin was washed thoroughly with methanol (MeOH), DMF, and dichloromethane (DCM); and dried in vacuo. IR analysis of the resin revealed no peak corresponding to the aldehyde of the starting resin. Resin 3 (200 $\mathrm{mg}$ ) was immersed in $n$-butanol $(1 \mathrm{ml})$ completely. $\mathrm{N}$, N-diisopropyl ethylamine (DIEA, $105 \mu \mathrm{l})$ and 9-chlorodeazapurine 4 (61 mg) were added to the reaction. The reaction mixture was shaken at $80{ }^{\circ} \mathrm{C}$ for 16 hours. The resin was washed thoroughly with MeOH and DCM and dried in vacuo. Resin $5(200 \mathrm{mg})$ was immersed in DCM $(1 \mathrm{ml})$, in which DIEA $(210 \mu \mathrm{l})$ and ethyl isocyanate $(47 \mu \mathrm{l})$ were added. The mixture was shaken at $22{ }^{\circ} \mathrm{C}$ for 16 hours. Afterwards, the resin was washed thoroughly with MeOH, DMF, and dichloromethane (DCM) and dried in vacuo. A portion of the resulting resin $(190 \mathrm{mg})$ was shaken in a mixture of trifluoroacetic acid: $\mathrm{H}_{2} \mathrm{O}: \mathrm{DCM}(45: 5: 50)(1 \mathrm{ml})$ at $22{ }^{\circ} \mathrm{C}$ for 30 minutes. The resin was removed by filtration and the filtrate was concentrated in vacuo, affording the crude 7 (50 mg). The crude product was purified by preparative HPLC equipped with a MS triggered fraction collector and the fractions containing product 7 were combined and lyophilized, affording pure 7 as trifluoroacetic acid salt (yield $20.1 \mathrm{mg}, \mathrm{MS} \mathrm{MH}^{+}=248.1$ (electron spray)). 